\title{
Intraseasonal Time Scales of Convection in GCMs
}

\author{
K. R. Sperber \\ J. M. Slingo
}

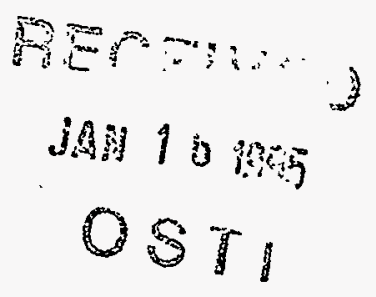

This paper was prepared for submittal to the Proceedings of the 20th Climate Diagnostic Workshop

Seattle, Washington

October 23-27, 1995

November 1995

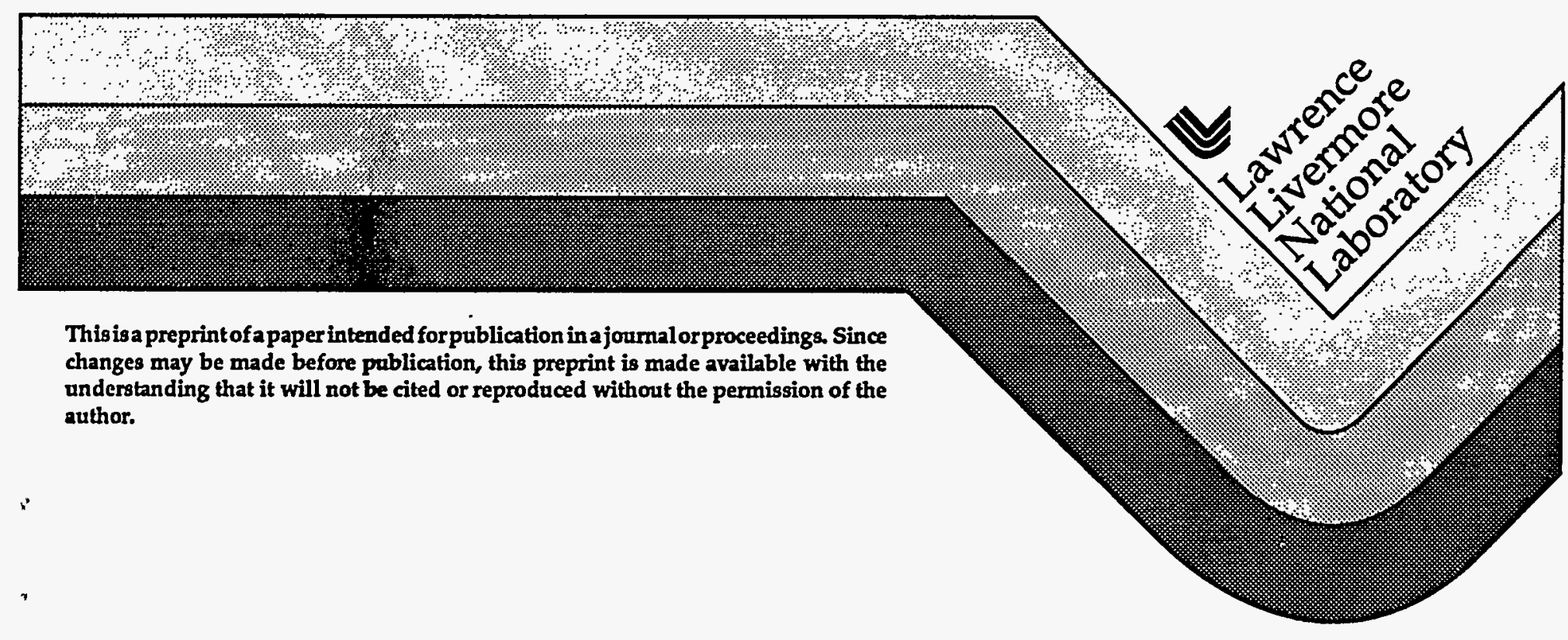




\section{DISCLAIMER}

This document was prepared as an account of work sponsored by an agency of the United States Government. Neither the United States Government nor the University of California nor any of their employees, makes any warranty, express or implied, or assumes any legal liability or responsibility for the accuracy, completeness, or usefulness of any information, apparatus, product, or process disclosed, or represents that its use would not infringe privately owned rights. Referenœ herein to any specific commercial product, process, or service by trade name, trademark, manufacturer, or otherwise, does not necessarily constitute or imply its endorsement, recommendation, or favoring by the United States Government or the University of California. The views and opinions of authors expressed herein do not necessarily state or reflect those of the United States Government or the University of California, and shall not be used for advertising or product endorsement purposes. 


\title{
INTRASEASONAL TIME SCALES OF CONVECTION IN GCMS
}

\author{
Kenneth.R. Sperber ${ }^{1}$ and Julia M. Slingo ${ }^{2}$ \\ ${ }^{1}$ Program for Climate Model Diagnosis and Intercomparison \\ Lawrence Livermore National Laboratory \\ P.0. Box 808, L-264, Livermore, CA 94551 \\ ${ }^{2}$ Department of Meteorology, Reading University \\ 2 Earley Gate, Whiteknights, P.O. Box 239 \\ Reading, RG6 2AU, United Kingdom
}

Recently, Slingo et al. (1996) evaluated the ability of 15 atmospheric general circulation models to simulate intraseasonal oscillations as part of a coordinated effort to investigate "Synoptic to Intraseasonal Time Scales" in models participating in the Atmospheric Model Intercomparison Project (AMIP, Gates 1992). From examination of daily upper tropospheric velocity potential and zonal wind $\left(10^{\circ} \mathrm{N}-10^{\circ} \mathrm{S}\right.$ averaged) from the 10 -year simulations we have found that no model has successfully captured the dominance of the intraseasonal oscillation (IO). When compared with the velocity potential wave number 1 power spectra from ECMWF analyses, all models fail to capture the observed broad spectral peak of 50-70 days. In most cases the variance at IO time scales is too weak while the models have a tendency to generate too much power (relatively) at higher frequencies. Also, they fail to properly partition the variance between eastward and westward modes. These shortcomings lead to IO propagation that is less coherent than observed. However, there are limited periods when a subset of the models exhibit IO variations that have reasonable periodicity and amplitude, and it is such cases that we concentrate on here to evaluate the ability of the models to simulate the convective evolution of the IO.

November 1987 through May 1988 was observed to be a period of particularly active intraseasonal variability (Matthews et al. 1996), which can be seen in the time-longitude plot of 20-100 day bandpass filtered upper-level velocity potential from ECMWF analyses, shown in Fig. 1. As we are interested in the convective response to passage of the active phase of the IO in the vicinity of the Austral monsoon, we average the filtered velocity potential between $100^{\circ}-140^{\circ} \mathrm{E}$ to create a time series of $\mathrm{IO}$ variability. This $\mathrm{IO}$ index is then correlated with seasonally detrended observed OLR. The correlations are computed using pentad averaged IO indices and OLR data at various lags to investigate the evolution of the convective response. To concisely represent this, in Fig. 1 we plot the lag at which the positive correlation (which indicates enhanced convection) between the IO index and the OLR is a maximum. Data is plotted at only those gridpoints at which the coefficient of correlation is significant at $\geq 95 \%$ confidence level. Clearly, at negative time lags the enhanced convection occurs to west of region from which we obtained our IO index, and subsequently the convective envelope propagates eastward, extending over Australia and influencing the SPCZ. While the spatial extent of the convective envelope varies somewhat from year to year, it consistently exhibits contiguous eastward propagation from the Indian Ocean through to the Maritime Continent.

The IO displays considerable interannual variability in its activity and, although Slingo et al. (1996) noted a possible link between the strength of the IO and the phase of ENSO, there was little indication from the models that the activity of the IO was systematically modulated by variations in the tropical SSTs. Thus, in order to show the models in their best light, we have examined all winters and selected that during which the IO was strongest and most coherent. 
Results from the GLA and UKMO, two models that exhibited the best IO variability of those examined by Slingo et al. (1996), are also shown in Fig. 1. The simulated time-longitude plots of their filtered upper-level velocity potential exhibit similar characteristics relative to the observations, but their convective responses are quite different in that both models fail to represent the coherent eastward convective evolution from the Indian Ocean to the Maritime Continent (this shortcoming also occurs in other years of the simulations, and is also seen in seasonal variance statistics on IO time scales). While they do exhibit eastward propagation of convection from the Maritime Continent into the western Pacific, the extent of the convective envelope is much more latitudinally confined than observed. Models with the weakest IO variability failed to simulate significant and coherent convective evolutions.

We wish to obtain further insight regarding the behavior of the intraseasonal oscillation in the strong versus weak models. If the IO is viewed as a moist Kelvin wave maintained by diabatic heating, as the current paradigm suggests, then models with reduced precipitation in the central Pacific will have conditions in which the wave is more quickly dissipated, and are thus less likely to maintain eastward propagation. To investigate this supposition we have considered the relationship between precipitation and SST in the region $140^{\circ} \mathrm{E}-180^{\circ} \mathrm{W}, 0^{\circ}-20^{\circ} \mathrm{S}$ during December-January-February since SSTs in excess of $29^{\circ} \mathrm{C}$ are found in this region. Figure 2a shows the DJF SST climatology during the AMIP decade (1979/ 80-1987/88), and Fig. 2b shows the scatter plot of MSU rainfall versus SST in the aforementioned region. Linear regression indicates that precipitation increases at the rate of $3.1(\mathrm{~mm} /$ day) $/{ }^{\circ} \mathrm{K}$, with a high degree of coherence between the rainfall and SST as reflected by their pattern correlation of 0.87 . The models with the strong IO variability [GLA, UKMO (Figs. 2c-d) and NCAR (not shown)] exhibit a similar rainfall/SST slope and nearly as robust pattern correlations noted in the observations. Those models with the weakest IO activity [ECMWF, MRI (Figs. 2c-d) and LMD (not shown)] tend to produce much less rainfall in this region, have slopes approximately one-half that observed and much weaker pattern correlations which indicates that their convective activity is not as strongly influenced by the SSTs. The following basic conclusion can been reached, that models with the most realistic intraseasonal oscillations appear to have precipitation distributions which are well correlated with warm SSTs, and that these models predominantly employ convective parametrizations which are closed on buoyancy rather than moisture convergence.

Acknowledgments. We would like to thank the AMIP modelling groups for making their output available. This work was performed under the auspices of the U.S. Department of Energy Environmental Sciences Division at the Lawrence Livermore National Laboratory under contract W-7405-ENG-48. Code for the computation of the filter weights was supplied by Dr. Mike Pedder (Reading University).

Gates, W. L., 1992: AMIP: The Atmospheric Model Intercomparison Project. Bull. Amer. Met. Soc., 73, 1962-1970.

Matthews, A. J., B. J. Hoskins, J. M. Slingo and M. Blackburn, 1996: Development of convection along the SPCZ within a Madden-Julian Oscillation. Q. J. Roy. Meteorol. Soc. (accepted).

Slingo, J. M., K. R. Sperber, J. S. Boyle, J.-P. Ceron, M. Dix, B. Dugas, W. Ebisuzaki, J. Fyfe, D. Gregory, J.-F. Gueremy, J. Hack, A. Harzallah, P. Inness, A. Kitoh, W. K.-M. Lau, B. McAvaney, R. Madden, A. Matthews, T. N. Palmer, C.-K. Park, D. Randall, N. Renno, 1996: Intraseasonal oscillations in 15 atmospheric general circulation models: Results from an AMIP diagnostic subproject. Clim. Dynam., (in press). 


\section{7/88 ECMWF/JDP Analyses/Observed OLR}
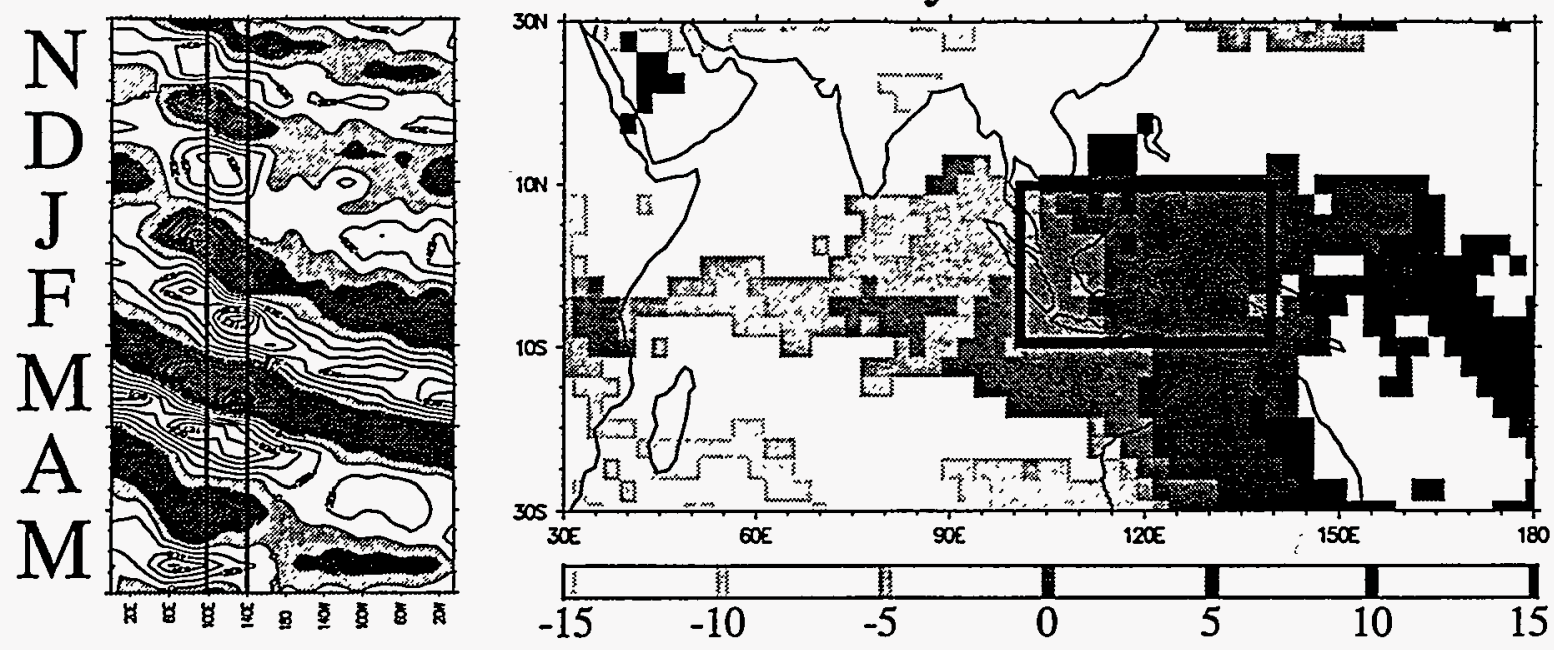

1986/87 GLA AMIP Simulation
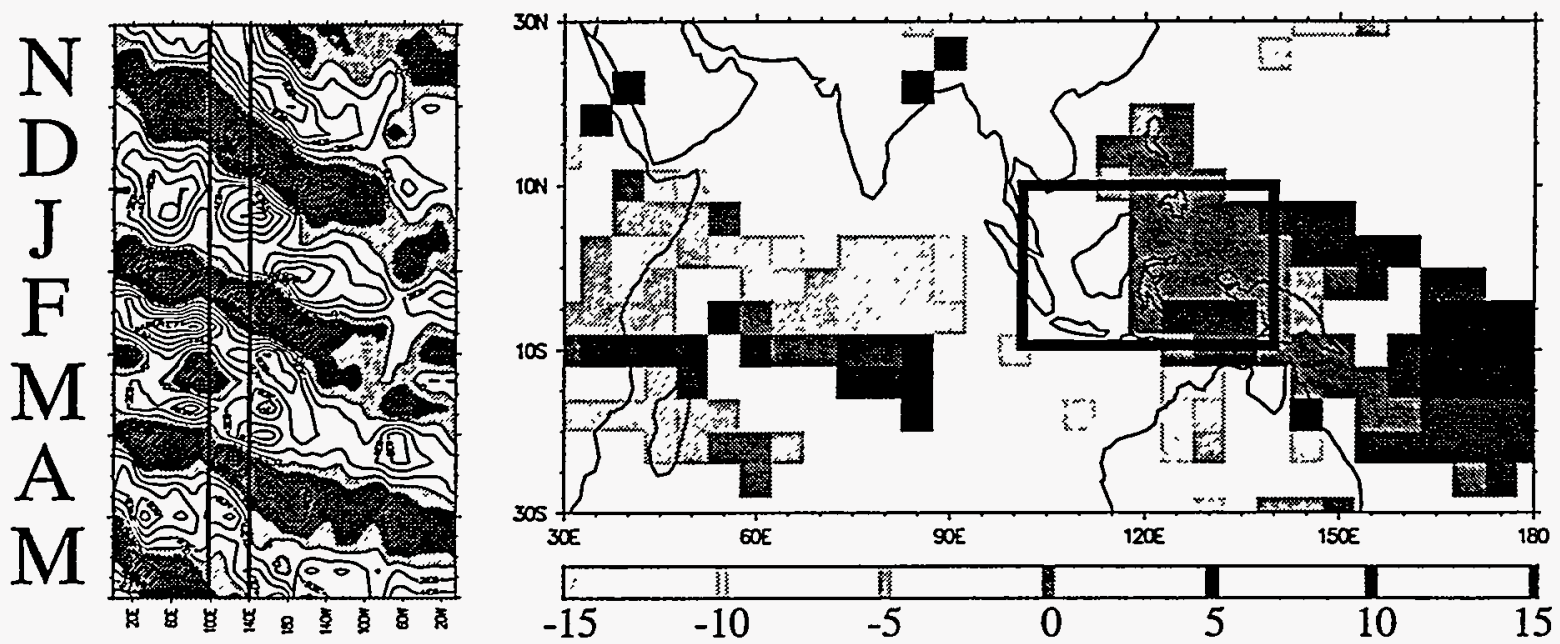

1980/81 UKMO AMIP Simulation
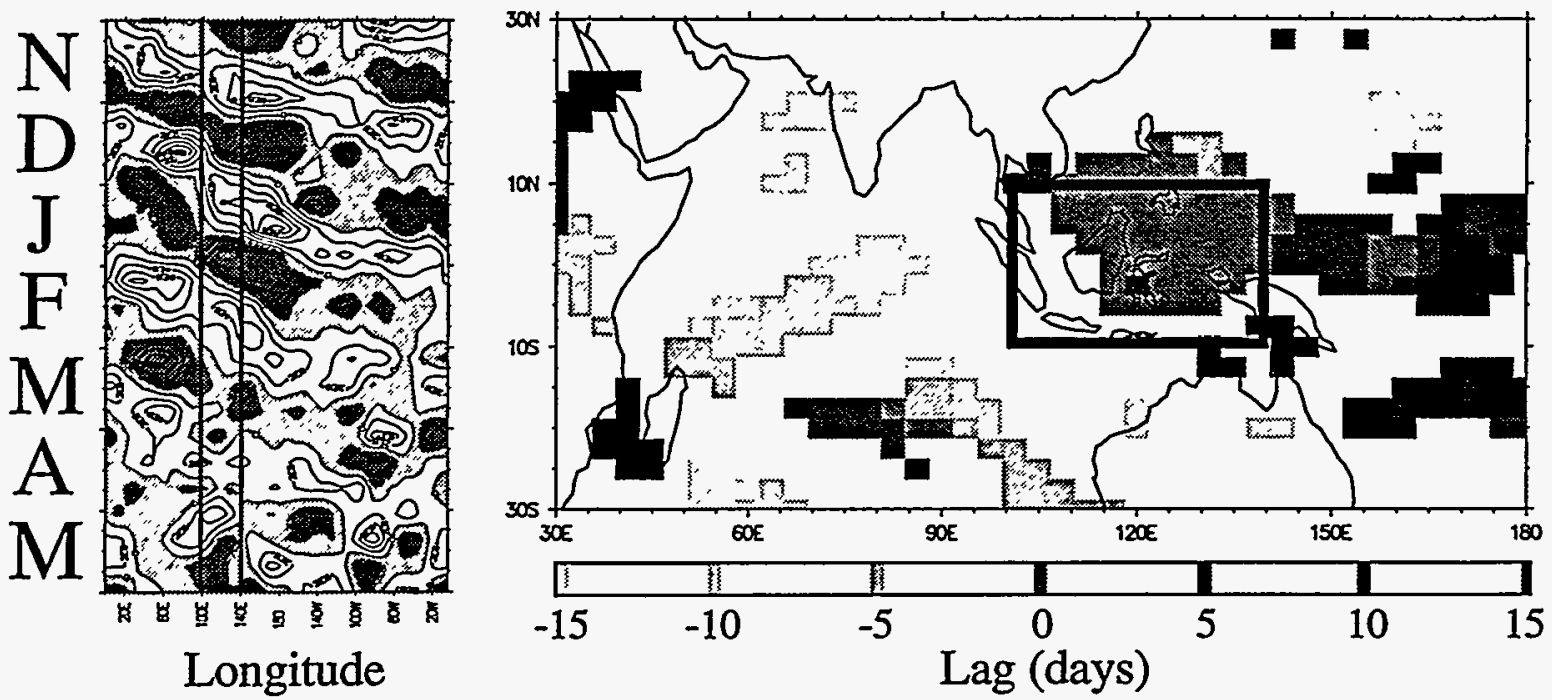

Fig. 1. Left panels: observed and simulated $10^{\circ} \mathrm{N}-10^{\circ} \mathrm{S}$ averaged $20-100$ day bandpass filtered upper-level velocity potential (enhanced upper level divergence shaded). When averaged between $100^{\circ}-140^{\circ} \mathrm{E}$ this provides an index of IO variability. Right panels: Lag at which the IO index and seasonally detrended OLR positive correlation is a maximum (if significant at $\geq 95 \%$ confidence level). This indicates the eastward propagation of enhanced convection associated with the passage of the active phase of the IO. 
a) DJF (1979/80-1987/88)

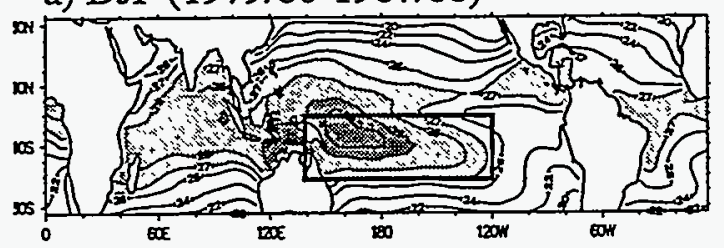

c)

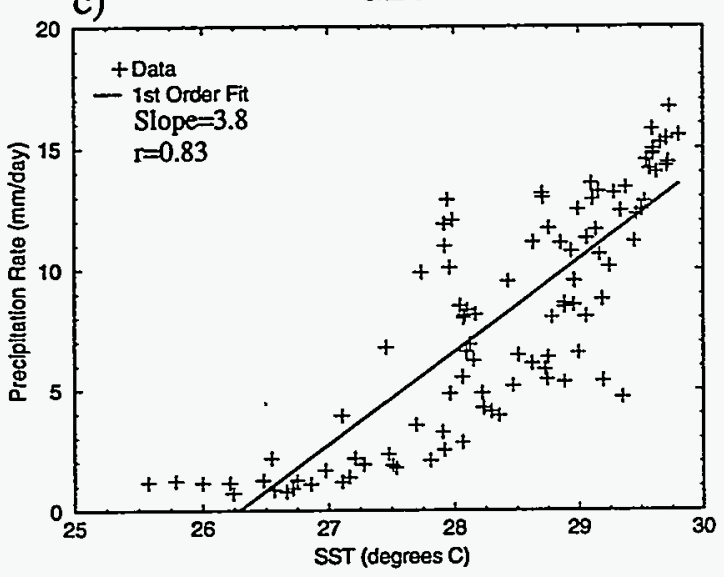

e)

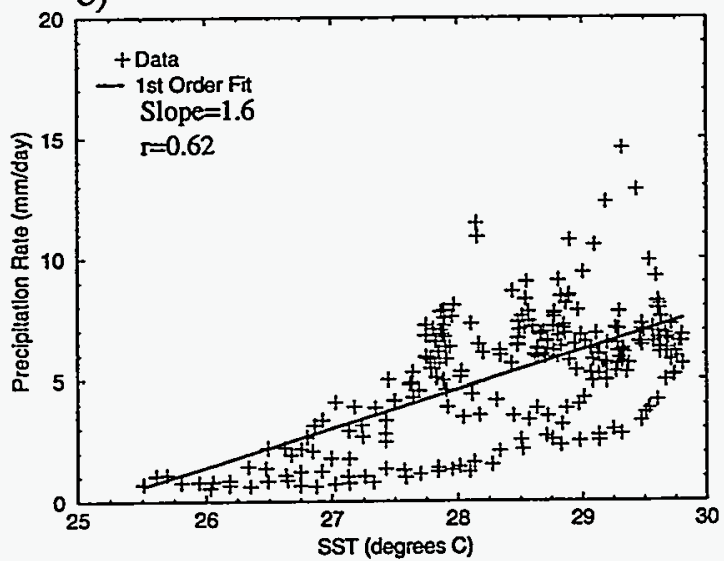

b)

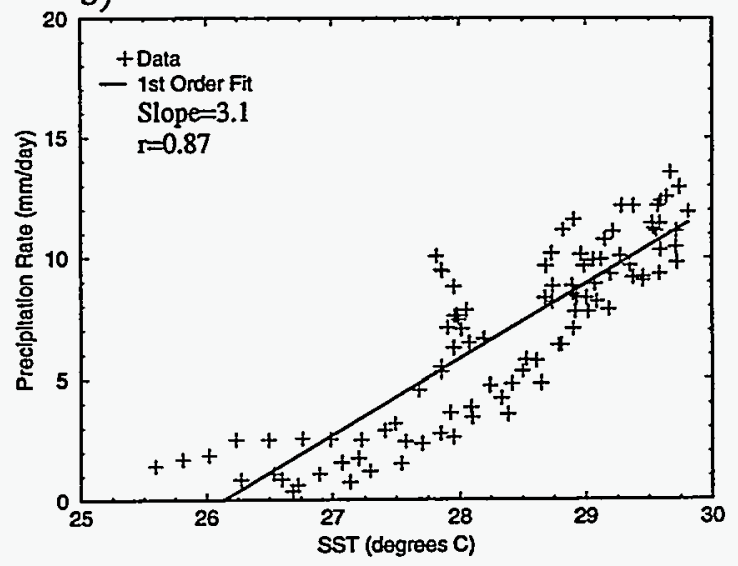

d)

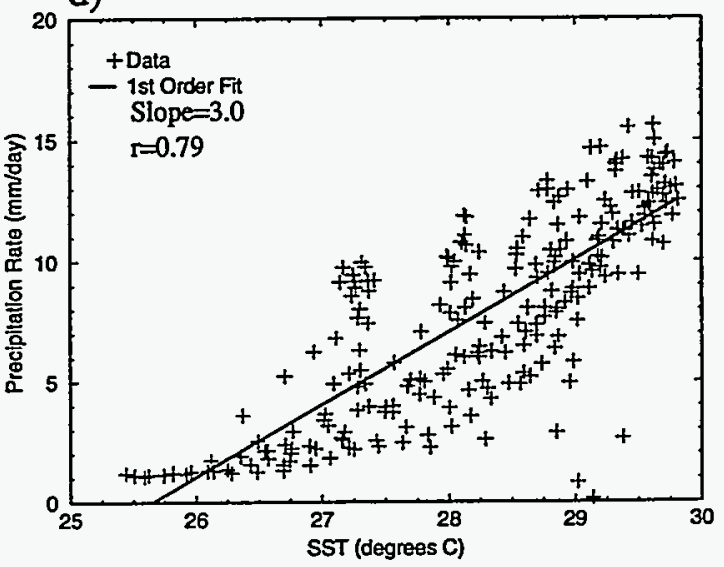

MRI

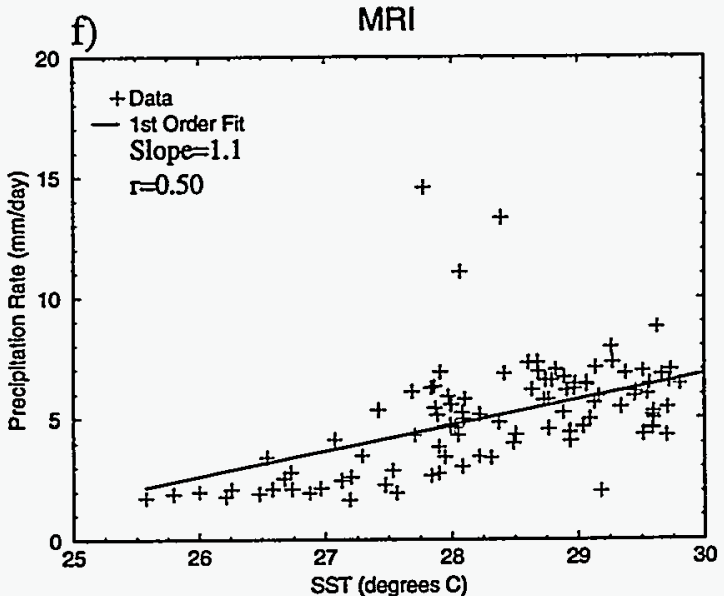

Fig. 2. 1979/80-1987/88 DJF a) SST climatology b) observed rainfall/SST relationship c) GLA rainfall/SST relationship d) UKMO rainfall/SST relationship e) ECMWF rainfall/SST relationship f) MRI rainfall/SST relationship. The GLA and UKMO (ECMWF and MRI) models exhibit strong (weak) intraseasonal variability. 